\title{
THE BARBARA WEINSTOCK LECTURES ON THE MORALS OF TRADE
}

Publications in this series, of which this is the nineteenth, contain essays by scholars and men of affairs dealing with various phases of the moral law in its bearing on business life under the new economic order, first given as lectures at the University of California on the Weinstock Foundation 
